\title{
Antimicrobial susceptibility and molecular characteristics of Mycoplasma pneumoniae isolates across different regions of China
}

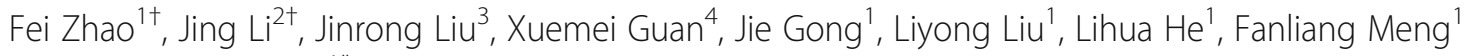
and Jianzhong Zhang ${ }^{* *}$

\begin{abstract}
Background: In China mainland, most Mycoplasma pneumoniae related studies are carried out in Beijing and Shanghai, while rare studies are performed in the other regions. In this study, we analyzed the molecular biology characteristics and antimicrobial susceptibility of clinical isolates of M. pneumoniae from 5 regions between January 2017 and December 2018.

Methods: Genotyping was performed to $154 \mathrm{M}$. pneumoniae isolates from 5 cities using PCR and multiple-locus variable-number tandem repeat analysis (MLVA) method. Antimicrobial susceptibility test was performed to all the isolates against 4 antibiotics. Sequencing was performed to the amplification products of the 235 rRNA drug resistant gene.

Results: Genotype I was detected in 118 M. pneumoniae isolates (76.6\%), and genotype II was identified in 36 isolates (23.4\%). The majority (92.2\%) of the MLVA genotypes were 4-5-7-2 and 3-5-6-2, which represented the genotype I and II, respectively. The total macrolide (ML) resistance rate was $79.7 \%$. The minimum inhibitory concentration (MIC) of the erythromycin was in a range of $128->256 \mu \mathrm{g} / \mathrm{ml}$, while that for the azithromycin was 2$32 \mathrm{\mu g} / \mathrm{ml}$. There were mutations in the $23 \mathrm{~S} \mathrm{rRNA}$ in each ML resistance isolate. Jilin city showed the highest prevalence of genotype I (100\%) and ML resistance rate (100\%), while Jinan showed the lowest prevalence of genotype I (45.5\%) and ML resistance rate (54.5\%).
\end{abstract}

Conclusions: A large variance was identified in the M. pneumoniae genotype and ML resistance among the 5 cities. The proportion of M. pneumoniae with a genotype II genotype (3-5-6-2) showed an increased trend.

Keywords: Mycoplasma pneumoniae, Macrolide resistance, 235 rRNA gene, Genotype

\section{Background}

Mycoplasma pneumoniae, an important pathogenic bacteria associated with respiratory tract infection in human, is responsible for about 10 to $40 \%$ of the community acquired pneumonia (CAP) [1, 2]. M. pneumoniae infection is usually considered as a self-limited disease, while a part of patients may develop severe pneumonia especially the children $[3,4]$.

\footnotetext{
* Correspondence: zhangjianzhong@icdc.cn

${ }^{\dagger}$ Fei Zhao and Jing Li contributed equally to this work.

${ }^{1}$ National Institute for Communicable Disease Control and Prevention,

Chinese Center for Disease Control and Prevention, State Key Laboratory of Infectious Disease Prevention and Control, 155 Changbai Road, Changping District, Beijing 102206, China

Full list of author information is available at the end of the article
}

Outbreak of M. pneumoniae infections also tends to occur in different regions with cyclic epidemics every 37 years. Since 2010, outbreak of M. pneumoniae has been reported in some European countries, including Denmark [5], Norway [6], Germany [7], United Kingdom and Wales [8], France [9] and Finland [6]. Afterwards, similar reports are available in Chile [10], Israel [11], Korea [12], Japan [13] and China [14]. Indeed, these studies reported the biological features of $M$. pneumoniae including population characteristics, genotype and antimicrobial susceptibility. Nevertheless, little is known about the relationship between $M$. pneumoniae epidemicity and genotype, antimicrobial susceptibility and

(c) The Author(s). 2019 Open Access This article is distributed under the terms of the Creative Commons Attribution 4.0 International License (http://creativecommons.org/licenses/by/4.0/), which permits unrestricted use, distribution, and reproduction in any medium, provided you give appropriate credit to the original author(s) and the source, provide a link to the Creative Commons license, and indicate if changes were made. The Creative Commons Public Domain Dedication waiver (http://creativecommons.org/publicdomain/zero/1.0/) applies to the data made available in this article, unless otherwise stated. 
virulence factors. This leads to urgent demands on the epidemiological and molecular analysis.

In China mainland, most of the M. pneumoniae related studies are conducted in Beijing and Shanghai [1519], while extremely rare studies are performed in the other regions. In a recent study, Xue et al. [20] firstly reported the M. pneumoniae genotype and antimicrobial resistance in 6 regions simultaneously. However, the $M$. pneumoniae genotype and antimicrobial resistance were derived from $M$. pneumoniae DNA detection, not from the clinical isolates. In this study, we analyzed the genotype and antimicrobial susceptibility of clinical isolates of M. pneumoniae from 5 regions between January 2017 and December 2018.

\section{Material and methods}

\section{M. pneumoniae strains}

M. pneumoniae strains were provided by the National Institute for Communicable Disease Control and Prevention, Chinese Center for Disease Control and
Prevention. A total of 154 strains were collected from 267 pediatric patients preliminarily confirmed with $M$. pneumoniae pneumonia in local hospitals in 5 cities from north to south of China, including Jilin (Jilin Province, China), Beijing, Jinan (Shandong Province, China), Fuyang (Anhui Province, China) and Soochow (Jiangsu Province, China) (Fig. 1). Each throat swab specimen was cultured in $2 \mathrm{ml}$ Mycoplasma selective liquid media (Bioreal Coming) at $37^{\circ} \mathrm{C}$. In cases of media color changing from red to yellow, $0.1 \mathrm{ml}$ suspension was transferred onto agar to subculture. Then $M$. pneumoniae isolates were purified using dilution technique. Nucleotide identification from each purified isolate was verified by Real-Time PCR as previously described [21].

\section{Real-time PCR-based genotyping}

Genotyping of M. pneumoniae was performed by RealTime PCR. Amplification of the specific regions of the genotype from all isolates was performed as previously described [22]. Real-time PCR was performed on the

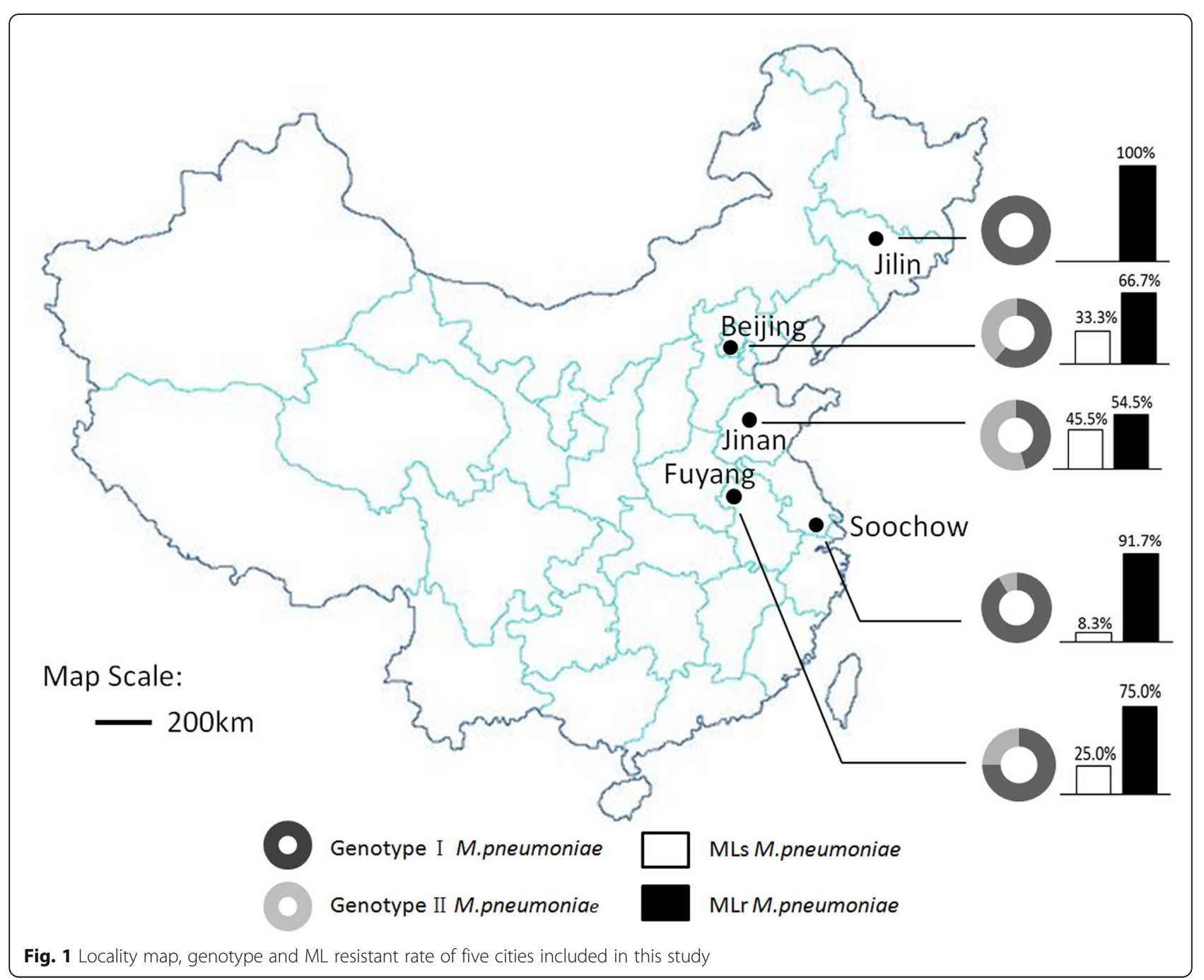


CFX96 system (Bio-Rad, Hercules, CA, USA). The amplification conditions were as follows: $95^{\circ} \mathrm{C}$ for $2 \mathrm{~min}$; followed by 45 cycles at $95^{\circ} \mathrm{C}$ for $15 \mathrm{~s}$ and $56^{\circ} \mathrm{C}$ for $15 \mathrm{~s}$. The data were analyzed with the CFX Manager Software (version 3.1; Bio-Rad).

\section{Multiple-locus variable-number tandem repeat analysis (MLVA) genotyping}

DNA was extracted from the 154 isolates using commercial QIAamp DNA MINI kit (QIAGEN, No. 51306), according to the manufacturer's instructions. The DNA was utilized as the template for Multiplex PCR amplification-linked capillary electrophoresis of four loci (i.e. Mpn13-16) selected for multilocus variable-number tandem-repeat (VNTR) analysis, according to the previous description with moderate modifications [23].

\section{Antimicrobial susceptibility testing}

Minimum inhibitory concentrations (MICs) against 4 antibiotics (i.e. erythromycin, azithromycin, levofloxacin and tetracycline) (Sigma-Aldrich, CA, USA) were determined using SP4 broth (Remel) based on the micro-dilution methods. M. pneumoniae M129 (ATCC 29342) and ICDC P028 (clinical isolate) served as macrolide-susceptible and -resistant controls, respectively. MIC was defined as the lowest concentration of antimicrobial agents that induced a color change in the control media. The MIC test was conducted based on the latest version of CSLI M43-A (2017 version). Sterilized liquid paraffin oil was utilized to seal the micro-plates, and then was incubated at $37^{\circ} \mathrm{C}$ for 5 days. All the susceptibility tests were performed at least in triplicate.

\section{Amplification and sequencing domains $\mathrm{V}$ of the $23 \mathrm{~S}$ rRNA} gene

Domain V of the 23S rRNA gene was amplified using the primers according to the previous study [24]. Each amplification was performed in a total volume of $20 \mu \mathrm{l}$, containing $2 \mu \mathrm{l} 10 \times$ Ex Taq Buffer $\left(\mathrm{Mg}^{2+}\right.$ plus $), 0.4 \mu \mathrm{M}$ primers, $1.6 \mu \mathrm{l}$ dNTP mixture, $0.2 \mu \mathrm{l}$ TaKaRa Ex Taq (5 $\mathrm{U} / \mu \mathrm{l})$, and $1 \mu \mathrm{l}$ of DNA template. Amplification was performed using the following conditions: $95^{\circ} \mathrm{C}$ for $3 \mathrm{~min}$; followed by 30 cycles of $95^{\circ} \mathrm{C}$ for $30 \mathrm{~s}, 55^{\circ} \mathrm{C}$ for $30 \mathrm{~s}$, and $72{ }^{\circ} \mathrm{C}$ for $60 \mathrm{~s}$; and $72{ }^{\circ} \mathrm{C}$ for $5 \mathrm{~min}$. After purification, the obtained products were sequenced using Sanger technique (Sangon Biotech, Beijing, China).

\section{Statistical analysis}

The data were entered into Excel 2007 sheet. Then SPSS 17.0 software was utilized for the statistical analysis. Chi square test was performed for the analysis of genotyping and drug resistance of strains isolated from different regions. $P$ value of less than 0.05 was considered to be statistically significant.

\section{Results}

\section{Real-time PCR genotyping}

Genotype I was detected in $118 \mathrm{M}$. pneumoniae isolates (76.6\%), and genotype II was identified in 36 isolates (23.4\%, Table 1$)$. The proportion of genotype I and II showed differences across various cities. The proportion of genotype I and II in Beijing was 60.8\% (31/51) and $39.2 \%$, respectively. The proportion of genotype I and II in Soochow was $91.7 \%(22 / 24)$ and $8.3 \%(2 / 24)$, respectively. In Fuyang, the proportions for genotype I and II were $75 \%(6 / 8)$ and $25 \%(2 / 8)$, respectively. In Jinan, the proportions were $45.4 \%(10 / 22)$ and $54.5 \%(12 / 22)$, respectively. In Jilin, the proportion for genotype I was

Table 1 Molecular characteristics of Mycoplasma pneumoniae from five areas in China

\begin{tabular}{|c|c|c|c|c|c|c|}
\hline & Total & Beijing & Jilin, JiLin & Soochow, Jiangsu & Jinan, Shangdong & Fuyang, Anhui \\
\hline M. pneumoniae isolates & 154 & 51 & 49 & 24 & 22 & 8 \\
\hline \multicolumn{7}{|l|}{ PCR genotypes } \\
\hline Genotype I & 118 & 31 & 49 & 22 & 10 & 6 \\
\hline Genotype ॥ & 36 & 20 & 0 & 2 & 12 & 2 \\
\hline \multicolumn{7}{|l|}{ MLVA genotypes } \\
\hline $4-5-7-2$ & 107 & 29 & 43 & 20 & 10 & 5 \\
\hline $4-5-7-3$ & 7 & 1 & 4 & 2 & 0 & 0 \\
\hline $4-4-7-2$ & 4 & 1 & 2 & 0 & 0 & 1 \\
\hline $3-5-6-2$ & 35 & 20 & 0 & 2 & 11 & 2 \\
\hline $3-6-6-2$ & 1 & 0 & 0 & 0 & 1 & 0 \\
\hline \multicolumn{7}{|l|}{ Macrolide } \\
\hline Resistance & 123 & 34 & 49 & 22 & 12 & 6 \\
\hline Sensitive & 31 & 17 & 0 & 2 & 10 & 2 \\
\hline
\end{tabular}


$100 \%$ (49/49), and no genotype II was identified. Statistical analysis indicated that there were significant differences in the genotype of the M. pneumoniae in different regions $\left(x^{2}=37.068, P<0.05\right)$. Taken together, the distribution of the two genotypes was different in these cities (Fig. 1).

\section{MLVA genotyping}

The most common MLVA genotype was 4-5-7-2 (69.4\%, 107/154), followed by genotype 3-5-6-2 (22.7\%, 35/154), 4-5-7-3 (4.5\%, 7/154), 4-4-7-2 (2.6\%, 4/154), and 3-6-6-2 $(0.6 \%, 1 / 154)$. Table 1 showed the MLVA genotyping of isolated obtained in each city. In terms of the traditional genotypes (i.e. genotype I and II), compared with the MLVA genotypes, more than $90 \%$ of the genotype I $M$. pneumoniae isolates belonged to 4-5-72 , and genotype II isolates belonged to $3-5-6-2$, respectively (Table 2).

\section{Antimicrobial susceptibility testing of $M$. pneumoniae} In total, 123 (79.9\%) were macrolide-resistant. The isolates collected in Jilin showed the highest macrolide-resistance rate $(100 \%)$, followed by Soochow (91.7\%), Fuyang (75\%), Beijing (66.7\%), and Jinan (54.5\%, Table 1, Fig. 1). There were significant differences in the ML resistance of $M$. pneumoniae in different regions $\left(x^{2}=28.851, P<0.05\right)$. The 123 macrolide-resistant isolates and the reference strain ICDCP028 were resistant to erythromycin (MIC $\geq 128 \mu \mathrm{g} / \mathrm{ml}$ ) and azithromycin (MIC 2-32 $\mu \mathrm{g} / \mathrm{ml}$ ). The other 31 isolates and reference strain M129 were susceptible to macrolide with a MIC of $\leq 0.008$ for erythromycin and azithromycin. Each isolate was susceptible to tetracycline and levofloxacin (Table 3) (Additional file 1).

\section{Amplification and sequencing domains $\mathrm{V}$ of the $23 \mathrm{~S}$ rRNA gene}

A2063G mutation in domain $\mathrm{V}$ of the 23S rRNA gene was identified in 121 (98.3\%) macrolide-resistant clinical isolates. Only two macrolide-resistant clinical isolates harbored the A2064G mutation in 23S rRNA gene. No domain $\mathrm{V}$ mutation was identified in 31 macrolide-susceptible clinical isolates. Furthermore, no other

Table 2 Relationship between traditional genotype and MLVA genotype of M. pneumoniae

\begin{tabular}{llll}
\hline Traditional & \multicolumn{2}{l}{ MLVA genotype } & \\
\cline { 2 - 4 } genotype & Genotype & Numbers & $\%$ \\
\hline Genoype I (118) & $4-5-7-2$ & 107 & 90.7 \\
& $4-5-7-3$ & 7 & 5.9 \\
Genotype II (36) & $4-4-7-2$ & 4 & 3.4 \\
& $3-5-6-2$ & 35 & 97.2 \\
& $3-6-6-2$ & 1 & 2.8 \\
\hline
\end{tabular}

mutations were found in domain $\mathrm{V}$ of the $23 \mathrm{~S}$ rRNA gene in all isolates (Table 3).

\section{Discussion}

We analyzed the molecular biological features and antimicrobial susceptibility of $M$. pneumoniae isolates in 5 cities in China mainland between January 2017 and December 2018. As is known to all, M. pneumoniae is classified into genotype I and genotype II according to the genome and proteomics data [25-27]. To further distinguish the genome information, Degrange et al. established the MLVA genotyping technique based on 5 loci (i.e. Mpn1 and Mpn13-16), with which M. pneumoniae was divided into dozens of genotypes [28]. Afterwards, such technique has been extensively utilized in the scientific research. However, Mpn1 locus with the highest efficiency in classification is unstable [29]. In 2010, the Mpn1 locus was no longer proposed by the ESCMID Study Group for Mycoplasma Infections [23], but the MLVA genotyping capacity of Mpn13-16 showed significant decline. Based on 10 articles [16, 28-36] involving 1,122 M. pneumoniae isolates, the replication copy of Mpn13 and Mpn15 were highly consistent with genotype I and II. Among the 1,122 isolates, 1,074 (95.7\%) with a replication copy of 4 and 7 for Mpn13 and Mpn15 loci showed genotype I, while those with a replication copy of 5 and 6 for Mpn13 and Mpn15 loci showed genotype II. In this study, the MLVA genotyping data were completely in line with these features, with more than $90 \%$ of the genotype I and II isolates showing a MLVA genotype of 4-5-7-2 and 3-5-6-2. This indicated that compared to the conventional genotyping technique, merely $7.8 \%(12 / 154)$ of the isolates with multiple genotypes could be divided using MLVA genotyping technique (Table 3). Recently, Xue et al. [20] investigated the MLVA genotypes of $M$. pneumoniae in Kunming City, which indicated that there was a base deletion (7 bp) in the repeats of Mpn15 in two patients. This imply that there are indeed some limitations in the current MLVA genotyping loci.

In this study, the most common M. pneumoniae genotype was genotype I (4-5-7-2), while the rest was genotype II (3-5-6-2). There were significant differences in the genotyping among the five cities. The proportion of genotype I in Jilin city was $100 \%$, while that in Jinan was merely $45.5 \%$. According to the previous description [20], in geographic locations, Jilin and Harbin localizing in the Northeast of China with a linear distance of about $200 \mathrm{~km}$ showed a genotype I prevalence of 100 and $71.4 \%$, respectively. In addition, the variations of genotypes in Nanjing and Shanghai with a linear distance of about $280 \mathrm{~km}$ were extremely large. Soochow, localizing at the middle of Nanjing and Shanghai in geography, showed a closer genotype I prevalence to Shanghai 
Table 3 Genotype characteristics and MIC ranges of four antimicrobial agents against $154 \mathrm{M}$. pneumoniae clinical isolates from five areas, 2017 to 2018

\begin{tabular}{|c|c|c|c|c|c|c|c|}
\hline \multirow[t]{2}{*}{ Region } & \multirow{2}{*}{$\begin{array}{l}\text { Mutation } \\
\text { in the } \\
23 \mathrm{~S} \text { rRNA }\end{array}$} & \multicolumn{2}{|c|}{ Isolates number } & \multicolumn{4}{|l|}{$\mathrm{MIC}(\mu \mathrm{g} / \mathrm{ml})$} \\
\hline & & Genotype I & Genotype II & ERY & AZM & LVX & TET \\
\hline \multirow[t]{2}{*}{ Beijing } & A2063G & 30 & 4 & $128->256$ & $2-32$ & $0.125-1$ & $0.016-0.125$ \\
\hline & None & 1 & 16 & $<0.008$ & $<0.008$ & $0.125-0.5$ & $0.032-0.125$ \\
\hline \multirow[t]{2}{*}{ Jilin, Jilin } & A2063G & 48 & 0 & $128->256$ & $2-32$ & $0.125-0.5$ & $0.016-0.25$ \\
\hline & A2064G & 1 & 0 & $>256$ & 2 & 0.5 & 0.125 \\
\hline \multirow[t]{2}{*}{ Soochow, Jiangsu } & A2063G & 22 & 0 & $\geq 256$ & $2-16$ & $0.125-1$ & $0.016-0.125$ \\
\hline & None & 0 & 2 & $<0.008$ & $<0.008$ & $0.25-0.5$ & 0.032 \\
\hline \multirow[t]{3}{*}{ Jinan, Shangdong } & A2063G & 8 & 3 & $128->256$ & $2-32$ & $0.125-1$ & $0.032-0.125$ \\
\hline & A2064G & 1 & 0 & 256 & 2 & 0.5 & 0.032 \\
\hline & None & 1 & 9 & $<0.008$ & $<0.008$ & $0.125-0.5$ & $0.016-0.125$ \\
\hline \multirow[t]{2}{*}{ Fuyang, Anhui } & A2063G & 6 & 0 & $>256$ & $4-16$ & $0.125-0.5$ & $0.032-0.125$ \\
\hline & None & 0 & 2 & $<0.008$ & $<0.008$ & $0.25-0.5$ & $0.032-0.125$ \\
\hline \multirow[t]{3}{*}{ Total } & A2063G & 114 & 7 & $128->256$ & $2-32$ & $0.125-1$ & $0.016-0.25$ \\
\hline & A2064G & 2 & 0 & $\geq 256$ & 2 & 0.5 & $0.032-0.125$ \\
\hline & None & 2 & 29 & $<0.008$ & $<0.008$ & $0.125-0.5$ & $0.016-0.125$ \\
\hline
\end{tabular}

The MIC of each agent was defined as the lowest concentration of each antibiotic that prevented the color change $E R Y$ erythromycin, AZM azithromycin, LVX levofloxacin, TET tetracycline

(91.7\% vs. $80 \%)$. The most high prevalence of $M$. pneumoniae genotype II in the five cities was Nanjing, with a prevalence of up to $80 \%$. In this study, the prevalence of genotype II in Beijing and Jinan, localizing at the north of Nanjing, was 54.5 and $33.3 \%$, respectively (Fig. 2). This implied that the distance may not be an important cause for variations in the $M$. pneumoniae genotypes.

The highest ML resistance proportion of isolates from Jilin, with the highest prevalence of genotype I, was $100 \%$. Jinan, with the lowest prevalence of genotype I, showed the lowest ML resistance proportion of $54.5 \%$. It seemed that ML resistance was correlated with the $M$. pneumoniae genotype (Tables 1 and 3, Fig. 1). Such phenomenon had been reported by other studies in China mainland $[15,17,37,38]$ rather than the other countries $[24,39,40]$. To date, the ML resistance of $M$. pneumoniae has been acknowledged to be associated with the mutations in 2617, 2063 and 2064 loci in $23 \mathrm{~s}$ rRNA [1, 41]. In this study, mutations on 2063 and 2064 loci were identified in the ML resistant strains, and no mutations were found in the ML susceptible strains. In a previous study, Okaziki et al. reported transition of $\mathrm{ML}$ susceptible to ML resistant $M$. pneumoniae strains in the presence of ML exposure. Meanwhile, there were point mutations at 2,063 and 2,064 of the $23 \mathrm{~s}$ rRNA gene, which resulted in stable phenotype-related antimicrobial resistance [42]. Therefore, the ML resistance of $M$. pneumoniae may be related to the antibiotics pressure to some extent, which was a gradual process. Nowadays, ML antibiotics have been commonly utilized in
Chinese population, especially children. What's more, abuse of ML antibiotics is also reported in some regions. In this study, the time span was short and was similar with the cross-sectional studies. Our data might not reflect the correlation between ML resistance and genotype of $M$. pneumoniae. However, our team performed 10-year cohort studies on the molecular characteristics and antimicrobial susceptibility of $M$. pneumoniae in Beijing. Between 2008 and 2012, the predominant genotype of $M$. pneumoniae was genotype I $[15,43]$. In 2013, the proportion of genotype II $M$. pneumoniae showed a trend of increase [44]. Between 2014 and 2016, the proportion of genotype II $M$. pneumoniae was in a range of 30 to $40 \%$ [45]. In this study, the proportion of genotype II M. pneumoniae in Beijing between 2017 and 2018 was $39.3 \%$. The prevalence of antimicrobially resistant genotype II $M$. pneumoniae in Beijing increased from 0 to $20 \%$ over the past decade $[44,45]$, which indicated that the prevalence of genotype II $M$. pneumoniae showed a gradual trend in the presence of antibiotics exposure. It seemed that the total antimicrobial resistance rates showed decline in Beijing [20,45], but in fact, the antimicrobial resistance proportion of genotype I strains was high with no trend of decline, while the proportion of antimicrobial resistance in genotype II showed gradual increase. The decline of total antimicrobial resistance rates may be related to the rapid increase of genotype II M. pneumoniae in Beijing within these years compared to the increase of its antimicrobial resistance. In 2016, Xue et al. [20] reported the proportion of genotype II $M$. 


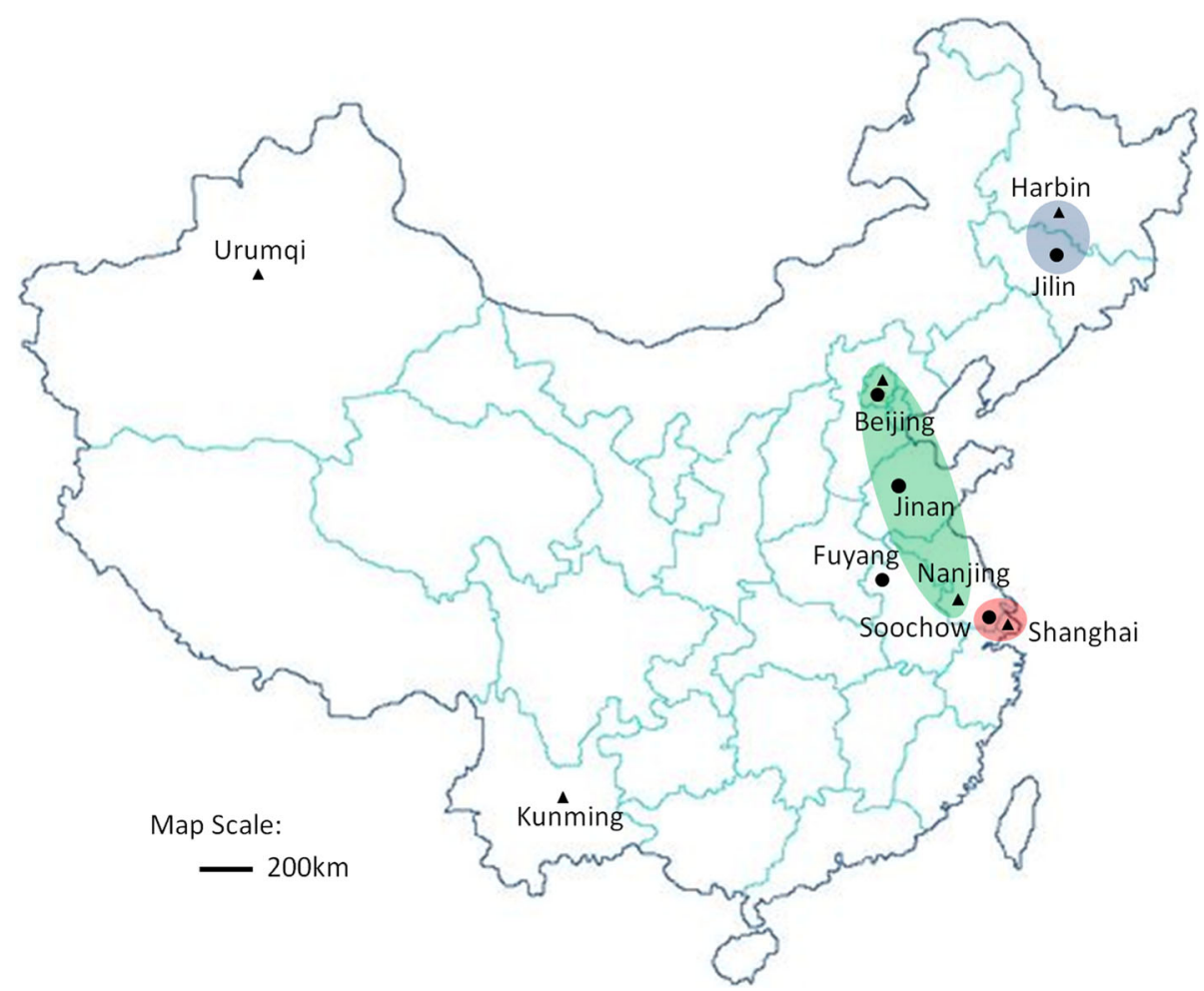

Fig. 2 Locality map of ten cities included in this study $(\bullet)$ and newly publication( $\boldsymbol{\Delta}$ Ref [21]). The genotyping and ML resistance were nearly the same in the cities in the cycle

pneumoniae in Beijing was lower than the reported data ( $10.9 \%$ vs. $39.3 \%)$, which may be related to the variations induced by population and determination methods. In future, more persistent studies are required in order to obtain more accurate data.

Although the total ML resistance rate of M. pneumoniae among the 5 cities were in a range of 54.4 to $100 \%$, the resistance rate of genotype I M. pneumoniae after genotyping was higher than $90 \%$ in all these regions (Table 4). The major causes for variations of the ML resistance were proportion and antimicrobial resistance rate of genotype II strains. There were only 2 genotype II strains isolated from Fuyang and Soochow, and then data analysis was not performed. The antimicrobial

Table 4 Prevalence of macrolide resistance and genotyping in M. pneumoniae clinical isolates in five cities

\begin{tabular}{|c|c|c|c|c|}
\hline \multirow[t]{2}{*}{ Region } & \multirow{2}{*}{$\begin{array}{l}\text { Total } \\
\text { macrolide } \\
\text { resistance } \\
\text { rate }\end{array}$} & \multirow[t]{2}{*}{$\begin{array}{l}\text { Percentage of } \\
\text { Genotype II \% }\end{array}$} & \multicolumn{2}{|c|}{$\begin{array}{l}\text { Macrolide resistance } \\
\text { rate\% }\end{array}$} \\
\hline & & & Genotype I & Genotype II \\
\hline Jilin, Jilin & 100 & $N$ & $100(49 / 49)$ & $N(-)$ \\
\hline Soochow, Jiangsu & 91.6 & 8.3 & $100(22 / 22)$ & $N(0 / 2)$ \\
\hline Fuyang, Anhui & 75 & 25 & $100(6 / 6)$ & $N(0 / 2)$ \\
\hline Beijing & 66.7 & 39.3 & $96.8(30 / 31)$ & $20(4 / 20)$ \\
\hline Jinan, Shangdong & 54.5 & 54.5 & $90(9 / 10)$ & $25(3 / 12)$ \\
\hline
\end{tabular}

resistance rate of the genotype II strains (MLVA, 3-5-62 genotype) in Beijing and Jinan were all higher than $20 \%$. This indicated that more studies are required to support the correlation between genotype II (MLVA, 35-6-2 genotype) and ML resistance. The proportion of genotype I and II strains in Jinan was similar. However, the rate of antimicrobial resistance of genotype I was $90 \%$, while that of the genotype II was merely $25 \%$. On this basis, we speculated that there might be a transmission between genotype I and II in Jinan, rather than the transmission from genotype II to genotype I. Our future studies will focus on it. Our study contributes to the understanding on the molecular epidemics of $M$. pneumoniae in China mainland, the drug resistance and clinical medication in different regions. In future, more studies involving a large sample size and more monitoring sites are required.

\section{Bias and limitations}

There are some limitations in our study. Firstly, the sample size of strains in some regions was small. Secondly, the study duration was relatively short. It was similar to the cross-sectional study lacking of cohort studies. Thirdly, we only included five cities in this study, and our data could not represent the whole situation of $M$. pneumoniae infection in China mainland. 


\section{Conclusions}

In summary, we investigated the molecular characteristics of M. pneumoniae in 5 cities between January 2017 and December 2018. A large variance was identified in the $M$. pneumoniae genotype and ML resistance among the 5 cities. The proportion of $M$. pneumoniae with a genotype II (3-5-6-2) showed an increased trend, with an antimicrobial resistance of $0-25 \%$. In future, more studies are required to confirm the correlation between specific $M$. pneumoniae genotype and ML resistance.

\section{Additional file}

Additional file 1: All M. pneumoniae clinical isolates details from five cities. (XLSX $19 \mathrm{~kb}$ )

\section{Abbreviations}

AZM: azithromycin; CAP: community acquired pneumonia; ERY: erythromycin; LVX: levofloxacin; MICs: minimum inhibitory concentrations; ML: macrolide; MLVA: multilocus variable number tandem repeat analysis; TET: tetracycline; VNTR: variable-number tandem-repeat

\section{Acknowledgements}

We thank Professor Ming Fang from Shandong Center for Disease Control and Prevention and Professor Zhengrong Chen from Children's Hospital of Soochow University for the kind help in sample collection.

\section{Authors' contributions}

ZF wrote the manuscript; ZJZ revised the manuscript; LJ, LJR, GXM did the data analysis; GJ, LLY, HLH, MFL did the data collection. All authors read and approved the final manuscript.

\section{Funding}

This study was funded by the National Natural Science Foundation of China (Grant No. 81772154), The Major Infectious Diseases Such as AIDS and Viral Hepatitis Prevention and Control Technology Major Projects (Grant No. 2018ZX10712001) and Non-profit Central Research Institute Fund of Chinese Academy of Medical Sciences (Grant No. 2018RC310027).

\section{Availability of data and materials}

The datasets used and/or analysed during the current study are available from the corresponding author on reasonable request.

\section{Ethics approval and consent to participate}

This study was approved by the Research and Ethics Committee of National Institute for Communicable Disease Control and Prevention. The samples used in this study were throat swab specimen, which was non-invasive. Therefore, informed consent was obtained in an oral confirmation form. No written informed consent was obtained from the parents of each child. These samples were only used in this study with no commercial objectives. The parents of the children involved in the sample collection approved the preparation of the manuscript.

\section{Consent for publication}

Not applicable.

\section{Competing interests}

The authors declare that they have no competing interests.

\section{Author details}

${ }^{1}$ National Institute for Communicable Disease Control and Prevention, Chinese Center for Disease Control and Prevention, State Key Laboratory of Infectious Disease Prevention and Control, 155 Changbai Road, Changping District, Beijing 102206, China. ${ }^{2}$ Office of Laboratory Management, Chinese Center for Disease Control and Prevention, Beijing 102206, China. ${ }^{3}$ Department of Respiratory Medicine, Beijing Children's Hospital, National
Center for Children's Health, Capital Medical University, Nanlishi Road 56, Xicheng District, Beijing, China. ${ }^{4}$ Affiliated Hospital of Beihua University, Jilin 132011, China

Received: 8 April 2019 Accepted: 9 July 2019

Published online: 23 August 2019

\section{References}

1. Waites KB, Xiao L, Liu Y, Balish MF, Atkinson TP. Mycoplasma pneumoniae from the respiratory tract and beyond. Clin Microbiol Rev. 2017;30:747-809.

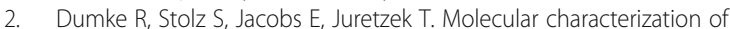
macrolide resistance of a mycoplasma pneumoniae strain that developed during therapy of a patient with pneumonia. Int J Infect Dis. 2014;29:197-9.

3. Cardinale F, Chironna M, Dumke R, Binetti A, Daleno C, Sallustio A, et al. Macrolide-resistant Mycoplasma pneumoniae in paediatric pneumonia. Eur Respir J. 2011;37:1522-4.

4. Youn YS, Lee KY.Mycoplasma pneumoniae pneumonia in children. Korean J Pediatr. 2012,55:42-7.

5. Uldum SA, Bangsborg JM, Gahrn-Hansen B, Ljung R, Molvadgaard M, Fons Petersen $\mathrm{R}$, et al. Epidemic of mycoplasma pneumoniae infection in Denmark, 2010 and 2011. Euro Surveill. 2012;17. PMID: 22321137.

6. Polkowska A, Harjunpaa A, Toikkanen S, Lappalainen M, Vuento R, Vuorinen $T$, et al. Increased incidence of mycoplasma pneumoniae infection in Finland, 2010-2011. Euro Surveill. 2012:17. PMID: 22321135.

7. Jacobs E, Ehrhardt I, Dumke R. New insights in the outbreak pattern of mycoplasma pneumoniae. Int J Med Microbiol. 2015;305:705-8.

8. Brown RJ, Nguipdop-Djomo P, Zhao H, Stanford E, Spiller OB, Chalker VJ. Mycoplasma pneumoniae epidemiology in England and Wales: a National Perspective. Front Microbiol. 2016;7:157.

9. Eibach D, Casalegno JS, Escuret V, Billaud G, Mekki Y, Frobert E, et al. Increased detection of mycoplasma pneumoniae infection in children, Lyon, France, 2010 to 2011. Euro Surveill. 2012;17. PMID: 22401503.

10. Martinez MA, Ruiz M, Zunino E, Luchsinger V, Aguirre R, Avendano LF. Identification of P1 types and variants of mycoplasma pneumoniae during an epidemic in Chile. J Med Microbiol. 2010;59:925-9.

11. Nir-Paz R, Abutbul A, Moses AE, Block C, Hidalgo-Grass C. Ongoing epidemic of mycoplasma pneumoniae infection in Jerusalem, Israel, 2010 to 2012 Euro Surveill. 2012;17. PMID: 22401504.

12. Kim EK, Youn YS, Rhim JW, Shin MS, Kang JH, Lee KY. Epidemiological comparison of three mycoplasma pneumoniae pneumonia epidemics in a single hospital over 10 years. Korean J Pediatr. 2015:58:172-7.

13. Okada T, Morozumi M, Tajima T, Hasegawa M, Sakata H, Ohnari S, et al. Rapid effectiveness of minocycline or doxycycline against macrolideresistant mycoplasma pneumoniae infection in a 2011 outbreak among Japanese children. Clin Infect Dis. 2012:55:1642-9.

14. Yan $\mathrm{C}$, Sun $\mathrm{H}$, Zhao H. Latest surveillance data on mycoplasma pneumoniae infections in children, suggesting a new epidemic occurring in Beijing. J Clin Microbiol. 2016:54:1400-1.

15. Cao B, Zhao CJ, Yin YD, Zhao F, Song SF, Bai L, et al. High prevalence of macrolide resistance in mycoplasma pneumoniae isolates from adult and adolescent patients with respiratory tract infection in China. Clin Infect Dis. 2010;51:189-94.

16. Zhao F, Liu G, Cao B, Wu J, Gu Y, He L, et al. Multiple-locus variable-number tandem-repeat analysis of 201 mycoplasma pneumoniae isolates from Beijing, China, from 2008 to 2011. J Clin Microbiol. 2013;51:636-9.

17. Xin D, Mi Z, Han X, Qin L, Li J, Wei T, et al. Molecular mechanisms of macrolide resistance in clinical isolates of mycoplasma pneumoniae from China. Antimicrob Agents Chemother. 2009;53:2158-9.

18. Liu Y, Ye X, Zhang H, Xu X, Li W, Zhu D, et al. Antimicrobial susceptibility of mycoplasma pneumoniae isolates and molecular analysis of macrolideresistant strains from Shanghai, China. Antimicrob Agents Chemother. 2009; 53:2160-2.

19. Liu $Y, Y e X$, Zhang $H, X u X$, Wang M. Multiclonal origin of macrolideresistant mycoplasma pneumoniae isolates as determined by multilocus variable-number tandem-repeat analysis. J Clin Microbiol. 2012;50:2793-5.

20. Xue G, Li M, Wang N, Zhao J, Wang B, Ren Z, et al. Comparison of the molecular characteristics of Mycoplasma pneumoniae from children across different regions of China. 2018;13:e0198557.

21. Dumke R, Schurwanz N, Lenz M, Schuppler M, Luck C, Jacobs E. Sensitive detection of mycoplasma pneumoniae in human respiratory tract samples by optimized real-time PCR approach. J Clin Microbiol. 2007;45:2726-30. 
22. Zhao F, Cao B, Li J, Song S, Tao X, Yin Y, et al. Sequence analysis of the p1 adhesin gene of mycoplasma pneumoniae in clinical isolates collected in Beijing in 2008 to 2009. J Clin Microbiol. 2011;49:3000-3.

23. Chalker VJ, Pereyre S, Dumke R, Winchell J, Khosla P, Sun H, et al. International mycoplasma pneumoniae typing study: interpretation of $\mathrm{M}$. pneumoniae multilocus variable-number tandem-repeat analysis. New Microbes New Infect. 2015;7:37-40.

24. Matsuoka M, Narita M, Okazaki N, Ohya H, Yamazaki T, Ouchi K, et al. Characterization and molecular analysis of macrolide-resistant mycoplasma pneumoniae clinical isolates obtained in Japan. Antimicrob Agents Chemother. 2004:48:4624-30.

25. Xiao L, Ptacek T, Osborne JD, Crabb DM, Simmons WL, Lefkowitz EJ, et al. Comparative genome analysis of mycoplasma pneumoniae. BMC Genomics. 2015;16:610

26. Lluch-Senar M, Cozzuto L, Cano J, Delgado J, Llorens-Rico V, Pereyre S, et al. Comparative "-omics" in mycoplasma pneumoniae clinical isolates reveals key virulence factors. PLoS One. 2015:10:e0137354.

27. Xiao D, Zhao F, Zhang H, Meng F, Zhang J. Novel strategy for typing mycoplasma pneumoniae isolates by use of matrix-assisted laser desorption ionization-time of flight mass spectrometry coupled with ClinProTools. J Clin Microbiol. 2014;52:3038-43.

28. Degrange S, Cazanave C, Charron A, Renaudin H, Bebear C, Bebear CM. Development of multiple-locus variable-number tandem-repeat analysis for molecular typing of mycoplasma pneumoniae. J Clin Microbiol. 2009;47: 914-23.

29. Benitez AJ, Diaz MH, Wolff BJ, Pimentel G, Njenga MK, Estevez A, et al. Multilocus variable-number tandem-repeat analysis of mycoplasma pneumoniae clinical isolates from 1962 to the present: a retrospective study. J Clin Microbiol. 2012;50:3620-6.

30. Yan $\mathrm{C}$, Sun $H$, Xue $G$, Zhao $H$, Wang $L$, Feng $Y$, et al. A single-tube multiplelocus variable-number tandem-repeat analysis of mycoplasma pneumoniae clinical specimens by use of multiplex PCR-capillary electrophoresis. J Clin Microbiol. 2014;52:4168-71.

31. Dumke R, Jacobs E. Culture-independent multi-locus variable-number tandem-repeat analysis (MLVA) of mycoplasma pneumoniae. J Microbiol Methods. 2011;86:393-6.

32. Xue G, Wang Q, Yan C, Jeoffreys N, Wang L, Li S, et al. Molecula characterizations of PCR-positive mycoplasma pneumoniae specimens collected from Australia and China. J Clin Microbiol. 2014;52:1478-82.

33. Qu J, Yu X, Liu Y, Yin Y, Gu L, Cao B, et al. Specific multilocus variablenumber tandem-repeat analysis genotypes of mycoplasma pneumoniae are associated with diseases severity and macrolide susceptibility. PLoS One. 2013;8:e82174

34. Pereyre S, Touati A, Petitjean-Lecherbonnier J, Charron A, Vabret A, Bebear C. The increased incidence of mycoplasma pneumoniae in France in 2011 was polyclonal, mainly involving M. pneumoniae type 1 strains. Clin Microb Infect. 2013:19:E212-7.

35. Kubota H, Okuno R, Hatakeyama K, Uchitani Y, Sadamasu K, Hirai A, et al. Molecular typing of mycoplasma pneumoniae isolated from pediatric patients in Tokyo, Japan. Jpn J Infect Dis. 2015;68:76-8.

36. Waller $J \mathrm{~L}$, Diaz MH, Petrone BL, Benitez AJ, Wolff BJ, Edison $L$, et al. Detection and characterization of mycoplasma pneumoniae during an outbreak of respiratory illness at a university. J Clin Microbiol. 2014;52 849-53.

37. Zhou Z, Li X, Chen X, Luo F, Pan C, Zheng X, et al. Macrolide-resistant mycoplasma pneumoniae in adults in Zhejiang, China. Antimicrob Agents Chemother. 2015;59:1048-51.

38. Qu J, Chen S, Bao F, Gu L, Cao B. Molecular characterization and analysis of mycoplasma pneumoniae among patients of all age with communityacquired pneumonia during an epidemic in China. Int J Infect Dis. 2019;83: 26-31.

39. Caballero Jde D, del Campo R, Mafe Mdel C, Galvez M, RodriguezDominguez M, Canton $\mathrm{R}$, et al. First report of macrolide resistance in a mycoplasma pneumoniae isolate causing community-acquired pneumonia in Spain. Antimicrob Agents Chemother. 2014;58:1265-6.

40. Spuesens EB, Meijer A, Bierschenk D, Hoogenboezem T, Donker GA, Hartwig $\mathrm{NG}$, et al. Macrolide resistance determination and molecular typing of mycoplasma pneumoniae in respiratory specimens collected between 1997 and 2008 in the Netherlands. J Clin Microbiol. 2012;50:1999-2004.

41. Pereyre S, Goret J, Bebear C. Mycoplasma pneumoniae: current knowledge on macrolide resistance and treatment. Front Microbiol. 2016;7:974.
42. Okazaki N, Narita M, Yamada S, Izumikawa K, Umetsu M, Kenri T, et al. Characteristics of macrolide-resistant mycoplasma pneumoniae strains isolated from patients and induced with erythromycin in vitro. Microbio Immunol. 2001;45:617-20.

43. Zhao F, Liu G, Wu J, Cao B, Tao X, He L, et al. Surveillance of macrolideresistant mycoplasma pneumoniae in Beijing, China, from 2008 to 2012. Antimicrob Agents Chemother. 2013;57:1521-3.

44. Zhao F, Liu L, Tao X, He L, Meng F, Zhang J. Culture-independent detection and genotyping of mycoplasma pneumoniae in clinical specimens from Beijing, China. PLoS One. 2015;10:e0141702.

45. Zhao F, Liu J, Shi W, Huang F, Liu L, Zhao S, et al. Antimicrobia susceptibility and genotyping of mycoplasma pneumoniae isolates in Beijing, China, from 2014 to 2016. Antimicrob Resist Infect Control. 2019;8:18

\section{Publisher's Note}

Springer Nature remains neutral with regard to jurisdictional claims in published maps and institutional affiliations.
Ready to submit your research? Choose BMC and benefit from:

- fast, convenient online submission

- thorough peer review by experienced researchers in your field

- rapid publication on acceptance

- support for research data, including large and complex data types

- gold Open Access which fosters wider collaboration and increased citations

- maximum visibility for your research: over $100 \mathrm{M}$ website views per year

At BMC, research is always in progress.

Learn more biomedcentral.com/submissions 